\title{
A Phase II Study of Imatinib in Patients with Advanced Anaplastic Thyroid Cancer
}

\author{
Huan T. Ha, Julia S. Lee, ${ }^{2}$ Susan Urba, ${ }^{1}$ Ronald J. Koenig, ${ }^{3}$ James Sisson, ${ }^{3}$ \\ Thomas Giordano, ${ }^{4}$ and Francis P. Worden ${ }^{1}$
}

Background: Currently, there is no standard treatment for metastatic anaplastic thyroid cancer (ATC). DNA microarray analysis has shown platelet-dervived growth factor receptor (PDGFR) overexpression in ATC relative to well-differentiated thyroid cancer. In p53-mutated/deficient ATC cell lines, cABL is overexpressed, and selective inhibition of cABL results in a cytostatic effect. Imatinib inhibits tyrosine kinase activity of Bcr-ABL and PDGF. We hypothesize that patients with ATC that over-expresses PDGF receptors or cABL will respond to imatinib.

Methods: Patients with histologically confirmed ATC who had measurable disease and whose disease expressed PDGF receptors by immunohistochemistry were eligible for study. Imatinib was administered at $400 \mathrm{mg}$ orally twice daily without drug holiday. Response to treatment was assessed every 8 weeks. Patients with complete response, partial responses, or stable disease were treated until disease progression. The study was terminated early due to poor accrual.

Results: From February 2004 to May 2007, 11 patients were enrolled and were started on imatinib. At baseline, 4/11 had locoregional disease, 5/11 had distant metastases, and 2/11 had both. Nine of 11 had prior chemoradiation, and $7 / 11$ had thyroidectomy. Eight of 11 were evaluable for response; 4 were excluded for lack of follow-up with radiologic evaluation. The overall response rates at 8 weeks were complete response $0 / 8$, partial response $2 / 8$, and stable disease $4 / 8$. The median time to follow-up was 26 months (ranges 23-30 months). The rate of 6-month progression-free survival was 36\% (95\% confidence interval, $9 \%-65 \%)$. The rate of 6-month overall survival was $45 \%$ ( $95 \%$ confidence interval, $16 \%-70 \%$ ). The most common grade 3 toxicity was edema in $25 \%$; other grade 3 toxicities included fatigue and hyponatremia ( $12.5 \%$ each). There were no grade 4 toxicities or treatment related deaths.

Conclusions: Imatinib appears to have activity in advanced ATC and is well tolerated. Due to difficulty of accruing patients with a rare malignancy at a single institution, further investigation of imatinib in ATC may be warranted in a multi-institutional setting.

\section{Introduction}

$\mathbf{T}$

HYROID CANCER IS a relatively rare malignancy. In 2008, there were $\sim 37,000$ new cases of thyroid cancer, resulting in 1590 deaths (1). Anaplastic thyroid cancer (ATC) comprises only about $1 \%-2 \%$ of all cases of thyroid cancer, but it accounts for $50 \%$ of thyroid-cancer-related mortality $(2,3)$. At presentation, $50 \%$ of ATC cases present with metastases, and $68 \%$ of patients will develop metastatic disease during the course of their disease (4). The majority of patients with ATC will develop pulmonary metastases $(2,5)$. The overall prog- nosis for patients with ATC is poor with median overall survival of 8 months for localized disease and 3 months for those with metastatic disease (5-8).

In the metastatic setting, single-agent doxorubicin results in a response rate of $\sim 20 \%$ (9). Combination chemotherapy regimens of doxorubicin with other cytotoxic agents such as bleomycin, vincristine, or melphalan do not significantly improve survival (5). More recently, paclitaxel was investigated as a single agent in a phase II study with an encouraging response rate of $58 \%$; however, the median survival of the study cohort as a whole was only 24 weeks (10).

\footnotetext{
${ }^{1}$ Division of Hematology/Oncology, Department of Internal Medicine; ${ }^{2}$ Cancer Center Biostatistics Unit; ${ }^{3}$ Division of Endocrinology, Department of Internal Medicine; ${ }^{4}$ Department of Pathology; University of Michigan, Ann Arbor, Michigan.
} 
A few pathways are thought to be vital for the pathogenesis of ATC. Preclinical data indicate that cABL plays a role in proliferation of fibroblasts lacking p53 (11). Using murine fibroblasts that were $\mathrm{p} 53^{-/-}$, Whang et al. showed that retroviral transduction of $\mathrm{CABL}$ increased fibroblast colony formation in $\mathrm{cABL}^{-/-} \mathrm{p} 53^{-/-}$mice. $\mathrm{p} 53$ deletion or mutation occurs in about $70 \%-85 \%$ of ATC. Several investigators have proposed that p53 abnormality transforms well-differentiated thyroid cancer into an anaplastic subtype (12-14). In preclinical models, imatinib inhibited growth of ATC cell lines (11,15-17).

Platelet-dervived growth factor receptor (PDGFR) is also vital in the pathogenesis of ATC. In the 1980s, PDGFR was noted to be present in different ATC cell lines, and stimulation of the receptor with PDGF resulted in internalization and growth of the cell line HTh $74(18,19)$. In our own institution, gene expression profiles derived from DNA microarray analysis have been obtained using Affymetrix GeneChips from two human ATCs, as well as four normal thyroids, seven papillary thyroid cancers, and eight thyroids with benign disease (multinodular goiter or adenoma). The relative expression level of PDGFR- $\beta$ showed an approximate 10-30fold increase in anaplastic carcinoma compared to normal thyroid, papillary carcinoma, and multinodular hyperplasia (T. Giordano, unpublished result).

Imatinib is a protein-tyrosine kinase inhibitor that targets $\mathrm{Bcr}-\mathrm{Abl}$ and c-kit/platelet derived growth factor receptor (PDGFR) tyrosine kinases. Its favorable toxicity profile and oral formulation facilitate its clinical application in a wide variety of malignancies, including chronic myelogneous leukemia and gastrointestinal stromal tumors. Given the lack of therapeutic options for advanced ATC and the preclinical rationale to target $\mathrm{CABL}$ and PDGF in ATC, we conducted a pilot study to evaluate the effectiveness of imatinib in patients with advanced ATC whose tumors overexpress PDGFR or cABL.

\section{Patients and Methods}

\section{Patient population}

All eligible patients had histological confirmation of ATC, overexpressing PGDFR as determined by immunohistochemistry using formalin-fixed, paraffin-embedded tissues. Each patient had measurable disease as determined by Response Evaluation Criteria in Solid Tumors (20). All had Zubrod performance scores of $\geq 70 \%$ with a life expectancy of at least 12 weeks. Patients were required to have adequate bone marrow function, with absolute neutrophil counts of $\geq 1500$ / $\mu \mathrm{L}$ and platelets of $\geq 100,000 / \mu \mathrm{L}$, and adequate renal and hepatic function, with a creatinine $\leq 1.5 \times$ institutional upper limit of normal (IULN), bilirubin $\leq 1.5 \times$ IULN, and aspartate aminotransferase/alanine transaminase $\leq 2.5 \times$ IULN, respectively. Prior chemotherapy, chemoradiation, radiation therapy, or surgeries were permitted if they were completed 28 days before registration.

This protocol was approved by the University of Michigan Institutional Review Board, and all patients provided written informed consent.

\section{Imatinib supply}

Novartis Pharmaceuticals Corporation provided imatinib (100 mg capsules) for this study during the first 12 months of therapy.

\section{Treatment plan}

Imatinib $400 \mathrm{mg}$ was administered orally twice daily with food. Toxicities were classified according to the Common Terminology Criteria for Adverse Events (version 2.0) (21). Clinical assessments took place every 4 weeks. Complete blood counts and serum chemistries were obtained every 2 weeks for the initial 16 weeks and then every 4 weeks thereafter. Dose modification of imatinib was delineated according to the severity of the adverse effects. Patients who developed $>$ grade 3 or recurrent $>$ grade 3 nonhematologic toxicity had imatinib withheld until the toxicity had resolved to < grade 1 , and the daily dose was reduced to $300 \mathrm{mg}$ once daily for patients receiving $400 \mathrm{mg}$ of imatinib, $400 \mathrm{mg}$ for patients receiving $600 \mathrm{mg}$ of imatinib, or $600 \mathrm{mg}$ for patients receiving $800 \mathrm{mg}$. For grade $3 / 4$ hematological toxicity, defined as an absolute neutrophil counts $<1 \times 10^{9} / \mathrm{L}$ or a platelet count $<50 \times 10^{9} / \mathrm{L}$, imatinib was withheld until the toxicity had resolved to <grade 2 . Dosages were then adjusted as noted above. No dose interruption or reduction was needed for grade $1 / 2$ hematological toxicities or grade $3 / 4$ anemia.

\section{Study evaluation}

Computed tomography or magnetic resonant imaging of neck and chest were obtained at baseline. Tumor response was assessed every 8 weeks (for the first 16 weeks, then every 3 months thereafter), using the same imaging modality that was obtained at baseline. The Response Evaluation Criteria in Solid Tumors (20) was used to assess response. To be considered evaluable for response, patients must have completed radiologic imaging following 8 weeks of imatinib. Any patient who had at least one dose of imatinib was considered evaluable for toxicicity.

\section{Statistical methods}

The primary objective of this trial was to estimate the response rate associated with imatinib treatment in patients with advanced ATC. The study was powered by the optimal two-stage accrual design (22) based on the criteria of stopping the trail if true response rate was $5 \%$ or lower and rejecting the null hypothesis if the true response rate was $20 \%$ or higher. The study planed to accrue 10 response-evaluable subjects during the first stage and 19 additional subjects during the second stage for a total of 28 subjects. If no responses were seen in the first stage, the trial would stop. Otherwise, an additional 19 response-evaluable patients would be entered. The trial advanced to the second stage but was terminated after 11 patients due to slow enrollment. Subjects completing two cycles of treatment were considered evaluable. The design provided at least an $80 \%$ statistical power and at most a $5 \%$ overall type I error rate.

The analysis was descriptive in nature. Mean, median, and frequency counts were reported for demographic, clinical variables, and toxicity. The Kaplan-Meier method was used to compute median follow-up time, to estimate of time to progression, to estimate progression-free survival, and to estimate the overall survival. Time to progression was defined as the time to disease progression where the event was true disease progression. Progression-free survival was defined as the time to either disease progression or to death due to any 
Table 1. Patient Characteristics

\begin{tabular}{|c|c|c|}
\hline Characteristic & No. of enrolled patients & $\%$ \\
\hline Total & 11 & 100 \\
\hline \multicolumn{3}{|l|}{ Gender } \\
\hline Male & 6 & 55 \\
\hline Female & 5 & 45 \\
\hline \multicolumn{3}{|l|}{ Age (years) } \\
\hline Median & 65 & \\
\hline Range & $53-79$ & \\
\hline \multicolumn{3}{|l|}{ Distant metastases } \\
\hline Lungs & 6 & 55 \\
\hline Ribs & 1 & 9 \\
\hline \multicolumn{3}{|l|}{ Previous therapy } \\
\hline Thyroidectomy & 7 & 64 \\
\hline \multicolumn{3}{|l|}{ Chemoradiation } \\
\hline Doxorubicin & 6 & 55 \\
\hline Nondoxorucicin & 3 & 27 \\
\hline Noncytotoxic & 2 & 18 \\
\hline
\end{tabular}

reason; events were disease progression and death. All analysis was conducted using SAS v9.1 (23).

\section{Results}

\section{Patient characteristics}

Between February 13, 2004, and May 10, 2007, 11 patients were enrolled. All 11 patients had overexpression of PDGFR by immunohistochemistry. Patient characteristics are listed in Table 1. Eight patients completed 8 weeks of imatinib and were considered evaluable for response. There were six men and five women, and the median age was 65 years (ranges 53-79). All had a Zubrod performance status $\geq 70 \%$. At baseline, $4 / 11$ patients $(36 \%)$ had locoregional disease, $6 / 11$ patients $(55 \%)$ had distant metastases, and $2 / 11$ patients $(18 \%)$ had both. Two of 11 patients received second-line systemic therapies, one with sorafenib, and one with combretastatin.

\section{Toxicity}

Toxicities from therapy are noted in Table 2. The most common grade 3 toxicity was edema in $25 \%$; other grade 3 toxicities included fatigue and hyponatremia (12.5\% each). There were no grade 4 or 5 toxicities reported. Three patients required dose attenuation to $300 \mathrm{mg}$ twice daily for the following adverse events: grade 3 hyponatremia (1/11), grade 3 periorbital edema $(1 / 11)$, and persistent grade 1 fatigue and nausea $(1 / 11)$. No patients required dosage reductions lower than $300 \mathrm{mg}$ twice daily.

\section{Treatment and tolerance}

The median duration of therapy for this study was 120 days (range 2-694 days). For those patients achieving disease stability, the average duration of imatinib treatment was 259 days. One 53-year-old male patient with recurrent, locally advanced disease, who initially underwent thyroidectomy without postoperative chemoradiation, attained a partial responses (PRs) for 120 days. Another patient, a 61-year-old woman with recurrent, locally advanced disease, achieved a PR for 694 days. Imatinib was discontinued due to progressive dysphagia, which was not related to her disease or study medication. Today, these two patients remain alive off of therapy.
Table 2. Common Toxicities

\begin{tabular}{|c|c|c|}
\hline \multirow[b]{2}{*}{ Toxicity } & \multicolumn{2}{|c|}{ No. of patients } \\
\hline & Grade 1-2 & Grade 3 \\
\hline \multicolumn{3}{|l|}{ Hematologic } \\
\hline Lymphopenia & 5 & 5 \\
\hline Anemia & 6 & 2 \\
\hline Thrombocytopenia & 1 & 0 \\
\hline \multicolumn{3}{|l|}{ Nonhematologic } \\
\hline Anorexia & 3 & 1 \\
\hline Weight loss & 3 & 0 \\
\hline Fatigue & 6 & 1 \\
\hline Infection without neutropenia & 3 & 1 \\
\hline Skin rash & 3 & 0 \\
\hline Allopecia & 1 & 0 \\
\hline Brusing & 3 & 0 \\
\hline Allergic rhinitis & 1 & 0 \\
\hline Dysphagia & 3 & 1 \\
\hline Nausea/vomiting & 4 & 2 \\
\hline Diarrhea & 3 & $\overline{0}$ \\
\hline Abdominal pain & 1 & 0 \\
\hline Melena & 1 & 1 \\
\hline Pericardial effusion & 0 & 1 \\
\hline Chest pain & 3 & 0 \\
\hline Pleural effusion & 0 & 1 \\
\hline Cough & 5 & 0 \\
\hline Hemoptysis & 2 & 0 \\
\hline Dyspnea & 5 & 1 \\
\hline Myalgia/arthralgia & 8 & 2 \\
\hline Hypoxia & 1 & 1 \\
\hline Urinary urgency & 2 & 0 \\
\hline Edema & 5 & 3 \\
\hline Electrolyte abnormality & 7 & 2 \\
\hline Dehydration & 1 & 1 \\
\hline Elevated creatinine & 2 & 0 \\
\hline Hypoglycemia & 2 & 0 \\
\hline Hyperglycemia & 4 & 0 \\
\hline Abnormal liver function tests & 8 & 0 \\
\hline Hypertension & 1 & 0 \\
\hline Hypothyroidism & 2 & 0 \\
\hline Syncope & 0 & 2 \\
\hline Ataxia & 1 & $\overline{0}$ \\
\hline Blurry vision & 1 & 1 \\
\hline Memory loss & 2 & 0 \\
\hline Mood change & 3 & 0 \\
\hline Change in mental status & 1 & 0 \\
\hline
\end{tabular}

\section{Response to treatment}

Out of 11 patients, 8 were evaluable for response. The overall response rates at 8 weeks were complete response $0 / 8$, PR 2/8 (25\%), and stable disease $4 / 8$ (50\%). The median follow-up time was 32.7 months (95\% confidence interval $[\mathrm{CI}]=28.9-36.5$ months). The estimate of 6 -month time to progression was $36 \%(9 \%-65 \%)$. The estimate of 6 -month progression-free survival was $27 \%$ (95\% CI, 7\%-54\%) (Fig. 1). The estimate of 6-month overall survival was $46 \%$ (95\% CI, $17 \%-71 \%$ ) (Fig. 2).

\section{Discussion}

This is the first published report of the use of imatinib in patients with recurrent, advanced or metastatic ATC who have failed front-line therapy with surgery and or definitive 


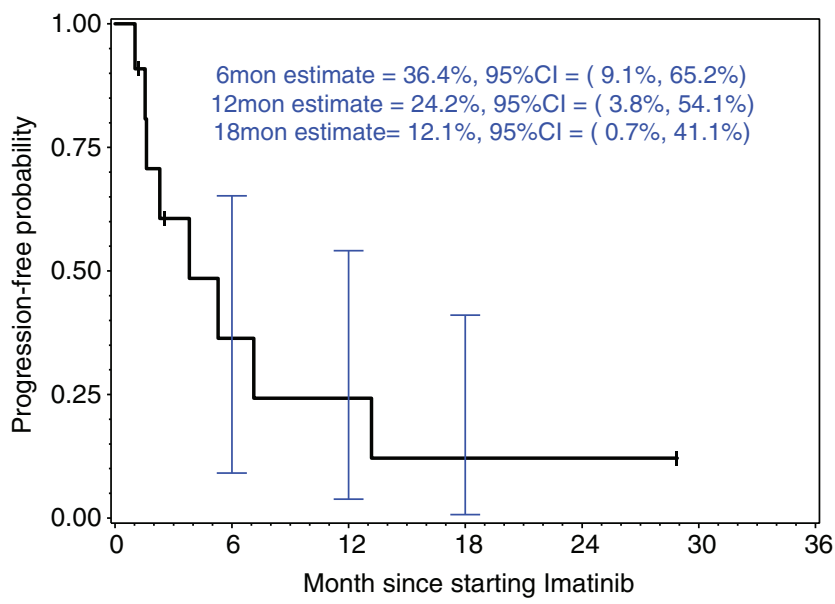

FIG. 1. Progression-free survival. CI, confidence interval. Color images available online at www.liebertonline .com/thy.

chemoradiation. Here we report rates of PR and disease stability at $25 \%$ and $50 \%$, respectively. Our results with imatinib are comparable to studies administering cytotoxic chemotherapy regimens for ATC. For example, doxorubicin when given to patients with advanced ATC produced a response rate of $20 \%(9)$. A similar response rate was seen with the use of paclitaxel, though the numbers of complete and PRs in this trial were somewhat higher than in our study (10). Overall, however, it is difficult to determine the effectiveness of imatinib, given the low number of patients that we treated. Unfortunately, our trial was terminated prematurely due to poor accrual, suggesting the importance of treating such orphan tumors in a multi-institutional setting.

Preclinical data by Podtcheko et al. suggest a strong rationale for targeting cABL and PDGF with imatinib (15). However, clinically, we observed no complete responses and few PRs with treatment. In a different preclinical model, the cytotoxic effects of imatinib were observed in nine different ATC cell lines (24). Cell viability was only minimally affected in $1 /$ 9 cell lines when treated with $10 \mu \mathrm{M}$ of imatinib, for which a therapeutic dosage of imatinib would not be feasible to ad-

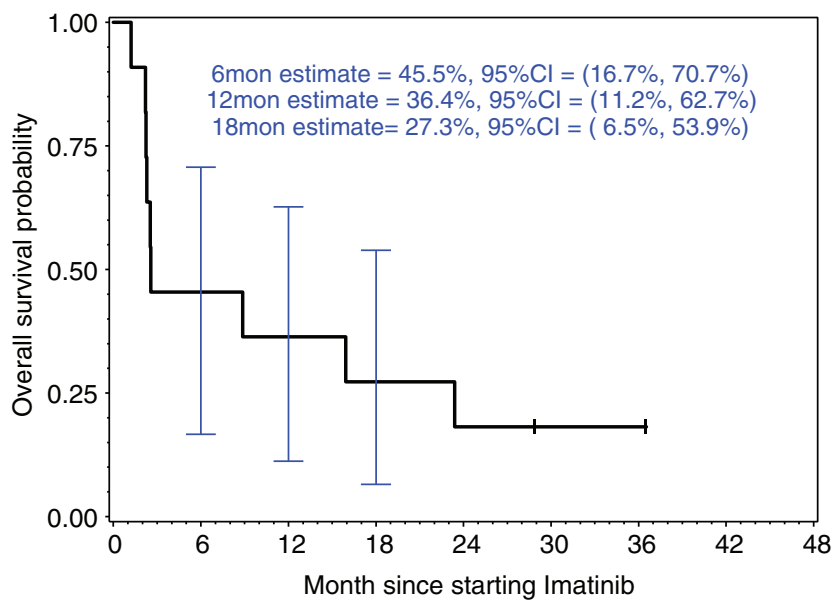

FIG. 2. Overall survival. Color images available online at www.liebertonline.com/thy. minister. One could then speculate that the dosage of imatinib in our trial was not adequate to induce a clinical response. Additionally, multidrug-resistant proteins (mrp) may play a role in inducing resistance to imatinib in ATC cell lines. Such resistance with imatinib has been well established in chronic myelogenous leukemia (CML) and gastrointestinal stromal tumor (GIST) $(25,26)$. Thus, mrp-1 overexpression in ATC may consequentially lead to resistance with imatinib. Future investigation of imatinib and other targeted therapies is needed to correlate the expression of mrp-1 and therapeutic outcomes.

Other tyrosine kinase inhibitors have been studied in patients with advanced ATC. In a preliminary report of 16 patients with advanced ATC who had progressed after treatment with frontline chemotherapy or chemoradiotherapy, Nagaiah et al. reported rates of PR and disease stability at $13 \%$ and $27 \%$, respectively, with sorafenib (27). The most common grade 3 and 4 toxicities reported were lymphopenia and rash with desquamation. Although the response rates are equally as low in this study as in our trial, the rate of disease stabilization is encouraging. Equally as encouraging are the limited numbers of grade 3 and 4 toxicities reported in each trial. The most frequent grade 3 event in our study was lymphopenia in $45 \%$ of patients. We also reported no grade 4 adverse events or treatment-related deaths. This observation is important, since the majority of patients who present with advanced ATC have markedly limited performance statuses, inhibiting them from receiving treatment with cytotoxic chemotherapy. The encouraging rates of disease stability in a tumor that is progressively fatal, in addition to the good tolerability of treatment, make the use of targeted therapies in ATC more appealing. Finally, other molecular pathways such as phosphoinositide 3-kinase (PI3K)/AKT/mammalian target of rapamycin (mTOR) appear to play a pathogenic role in $\operatorname{ATC}(28,29)$. With the current development of new mTOR inhibitors, clinical trials combining imatinib with such targeted agents are worth considering.

In addition to its use in the palliative setting, imatinib may play a role in radiation sensitization for patients with ATC. Aggressive local progression of disease places these patients at risk of suffocation. As such, improving local control is an important goal in the treatment of ATC. Palliative radiation therapy improves medial survival in patients with ATC, although marginally (4). The current standard of care for newly diagnosed locally advanced ATC is radiotherapay with weekly doxorubicin, which has been shown to improve local control and survival (30). Preclinical data by Podtcheko et al. suggest that imatinib may also have a radiosensitizing effect in ATC cell lines (31). Using two ATC cell lines, ARO and FRO, with mutated or deficient p53, both of which demonstrated sensitivity to imatinib, the investigators demonstrated a cytotoxic effect with the combination of imatinib and radiation therapy. Additionally, the combination of imatinib and cytotoxic chemotherapy with radiotherapy may also be feasible, since imatinib and chemotherapy have different therapeutic targets. An ongoing clinical trial evaluating the combination of imatinib with doxorubicin in GIST may provide some insight related to the effectiveness and toxicities of combining these two agents.

ATC is a rare and deadly disease with limited treatment options once patients have failed disease control with definitive chemoradiotherapy. Imatinib has encouraging activity in 
ATC and is well tolerated. A definitive conclusion regarding its clinical efficacy cannot necessarily be drawn from our study with so few patients. Nonetheless, we believe that imatinib may play a role in the treatment of patients with widely advanced or metastatic ATC, perhaps in combination with cytotoxic chemotherapy or other targeted agents. Thus, further investigations in a multi-institutional setting are warranted.

\section{Acknowledgments}

Supported in part from a grant from Novartis Pharmaceuticals Corporation.

\section{Disclosure Statement}

The authors declare that no competing financial interests exist.

\section{References}

1. Jemal A, Siegel R, Ward E, Hao Y, Xu J, Murray T, Thun MJ 2008 Cancer statistics, 2008. CA Cancer J Clin 58:71-96.

2. Ain KB 1998 Anaplastic thyroid carcinoma: behavior, biology, and therapeutic approaches. Thyroid 8:715-726.

3. Ain KB 1999 Anaplastic thyroid carcinoma: a therapeutic challenge. Semin Surg Oncol 16:64-69.

4. McIver B, Hay ID, Giuffrida DF, Dvorak CE, Grant CS, Thompson GB, van Heerden JA, Goellner JR 2001 Anaplastic thyroid carcinoma: a 50-year experience at a single institution. Surgery 130:1028-1034.

5. Are C, Shaha AR 2006 Anaplastic thyroid carcinoma: biology, pathogenesis, prognostic factors, and treatment approaches. Ann Surg Oncol 13:453-464.

6. Venkatesh YS, Ordonez NG, Schultz PN, Hickey RC, Goepfert H, Samaan NA 1990 Anaplastic carcinoma of the thyroid. A clinicopathologic study of 121 cases. Cancer 66:321-330.

7. Sugitani I, Kasai N, Fujimoto Y, Yanagisawa A 2001 Prognostic factors and therapeutic strategy for anaplastic carcinoma of the thyroid. World J Surg 25:617-622.

8. Besic N, Hocevar M, Zgajnar J, Pogacnik A, Grazio-Frkovic S, Auersperg M 2005 Prognostic factors in anaplastic carcinoma of the thyroid-a multivariate survival analysis of 188 patients. Langenbecks Arch Surg 390:203-208.

9. Ahuja S, Ernst H 1987 Chemotherapy of thyroid carcinoma. I Endocrinol Invest 10:303-310.

10. Ain KB, Egorin MJ, DeSimone PA 2000 Treatment of anaplastic thyroid carcinoma with paclitaxel: phase 2 trial using ninety-six-hour infusion. Collaborative Anaplastic Thyroid Cancer Health Intervention Trials (CATCHIT) Group. Thyroid 10:587-594.

11. Whang YE, Tran C, Henderson C, Syljuasen RG, Rozengurt $\mathrm{N}$, McBride WH, Sawyers CL $2000 \mathrm{c}-\mathrm{Abl}$ is required for development and optimal cell proliferation in the context of p53 deficiency. Proc Natl Acad Sci USA 97:5486-5491.

12. Zou M, Shi Y, Farid NR 1993 p53 mutations in all stages of thyroid carcinomas. J Clin Endocrinol Metab 77:1054-1058.

13. Lam KY, Lo CY, Chan KW, Wan KY 2000 Insular and anaplastic carcinoma of the thyroid: a 45-year comparative study at a single institution and a review of the significance of p53 and p21. Ann Surg 231:329-338.

14. Wiseman SM, Loree TR, Rigual NR, Hicks WL Jr., Douglas WG, Anderson GR, Stoler DL 2003 Anaplastic transformation of thyroid cancer: review of clinical, pathologic, and molecular evidence provides new insights into disease biology and future therapy. Head Neck 25:662-670.

15. Podtcheko A, Ohtsuru A, Tsuda S, Namba H, Saenko V, Nakashima M, Mitsutake N, Kanda S, Kurebayashi J, Yamashita S 2003 The selective tyrosine kinase inhibitor, STI571, inhibits growth of anaplastic thyroid cancer cells. J Clin Endocrinol Metab 88:1889-1896.

16. Kurebayashi J, Okubo S, Yamamoto Y, Ikeda M, Tanaka K, Otsuki T, Sonoo H 2006 Additive antitumor effects of gefitinib and imatinib on anaplastic thyroid cancer cells. Cancer Chemother Pharmacol 58:460-470.

17. Rao AS, Kremenevskaja N, von Wasielewski R, Jakubcakova V, Kant S, Resch J, Brabant G 2006 Wnt/beta-catenin signaling mediates antineoplastic effects of imatinib mesylate (gleevec) in anaplastic thyroid cancer. I Clin Endocrinol Metab 91:159-168.

18. Heldin NE, Gustavsson B, Claesson-Welsh L, Hammacher A, Mark J, Heldin CH, Westermark B 1988 Aberrant expression of receptors for platelet-derived growth factor in an anaplastic thyroid carcinoma cell line. Proc Natl Acad Sci USA 85:9302-9306.

19. Heldin NE, Cvejic D, Smeds S, Westermark B 1991 Coexpression of functionally active receptors for thyrotropin and platelet-derived growth factor in human thyroid carcinoma cells. Endocrinology 129:2187-2193.

20. Therasse P, Arbuck SG, Eisenhauer EA, Wanders J, Kaplan RS, Rubinstein L, Verweij J, Van Glabbeke M, van Oosterom AT, Christian MC, Gwyther SG 2000 New guidelines to evaluate the response to treatment in solid tumors. European Organization for Research and Treatment of Cancer, National Cancer Institute of the United States, National Cancer Institute of Canada. J Natl Cancer Inst 92:205-216.

21. National Cancer Institute 1993 Investigator's Handbook: A Manual for Participants in Clinical Trials of Investigational Agents Sponsored by DCTD, NCI. National Cancer Institute, Bethesda, MD.

22. Simon R 1989 Optimal two-stage designs for phase II clinical trials. Control Clin Trials 10:1-10.

23. Carey VJ 1997 Using hypertext and the Internet for structure and management of observational studies. Stat Med 16: 1667-1682.

24. Dziba JM, Ain KB 2004 Imatinib mesylate (gleevec; STI571) monotherapy is ineffective in suppressing human anaplastic thyroid carcinoma cell growth in vitro. J Clin Endocrinol Metab 89:2127-2135.

25. Lange T, Gunther C, Kohler T, Krahl R, Musiol S, Leiblein S, Al-Ali HK, van Hoomissen I, Niederwieser D, Deininger MW 2003 High levels of BAX, low levels of MRP-1, and high platelets are independent predictors of response to imatinib in myeloid blast crisis of CML. Blood 101:2152-2155.

26. Theou N, Gil S, Devocelle A, Julie C, Lavergne-Slove A, Beauchet A, Callard P, Farinotti R, Le Cesne A, Lemoine A, Faivre-Bonhomme L, Emile JF 2005 Multidrug resistance proteins in gastrointestinal stromal tumors: site-dependent expression and initial response to imatinib. Clin Cancer Res 11:7593-7598.

27. Nagaiah G, Fu P, Wasman JK, Cooney MM 2009 Phase II trial of sorafenib (bay 43-9006) in patients with advanced anaplastic carcinoma of the thyroid (ATC). J Clin Oncol 27(15 suppl).

28. Garcia-Rostan G, Costa AM, Pereira-Castro I, Salvatore G, Hernandez R, Hermsem MJ, Herrero A, Fusco A, CameselleTeijeiro J, Santoro M 2005 Mutation of the PIK3CA gene in anaplastic thyroid cancer. Cancer Res 65:10199-10207. 
29. Paes JE, Ringel MD 2008 Dysregulation of the phosphatidylinositol 3-kinase pathway in thyroid neoplasia. Endocrinol Metab Clin North Am 37:375-387, viii-ix.

30. Kim JH, Leeper RD 1987 Treatment of locally advanced thyroid carcinoma with combination doxorubicin and radiation therapy. Cancer 60:2372-2375.

31. Podtcheko A, Ohtsuru A, Namba H, Saenko V, Starenki D, Palona I, Sedliarou I, Rogounovitch T, Yamashita S 2006 Inhibition of ABL tyrosine kinase potentiates radiationinduced terminal growth arrest in anaplastic thyroid cancer cells. Radiat Res 165:35-42.
Address correspondence to:

Francis P. Worden, M.D.

University of Michigan Comprehensive Cancer Center 1500 East Medical Center Drive

SPC 5912

B1-364 CCC

Ann Arbor, MI 48109-5912

E-mail: fworden@med.umich.edu 
This article has been cited by:

1. Vicky Heath. 2010. Cancer: Tailored therapies for advanced thyroid cancers move a step closer. Nature Reviews Endocrinology 6:12, 651-651. [CrossRef] 